\title{
HPV-47-Induced and Tattoo-associated Verrucae Planae: Report of a Case and Review of the Literature
}

\author{
Nathalie Krecké $\cdot$ Sigrun Smola $\cdot$ Thomas Vogt · Cornelia Sigrid Lissi Müller
}

Received: June 20, 2017 / Published online: August 23, 2017

(c) The Author(s) 2017. This article is an open access publication

\begin{abstract}
The human papillomavirus (HPV), of which more than 200 different types have so far been identified, is an infectious disease impacting skin and mucous membranes. Several genera exist with distinct clinical impact. However, with ornamental tattoos increasing in popularity, a number of mostly cutaneous side effects have also been reported, such as infections, allergic reactions, or even a rise of malignant tumours within the tattoo. We report the first case of a $\beta 1-H P V$-type infection in cutaneous lesions in terms of verrucae vulgares near a tattoo in an immunocompetent adult without pre-existing conditions, and discuss possible relationships and etiologic concerns of this association.
\end{abstract}

Keywords: HPV; Human papillomavirus; Tattoo; Viral warts

Enhanced content To view enhanced content for this article go to http://www.medengine.com/Redeem/ E47AF0604364F861.

N. Krecké · T. Vogt · C. S. L. Müller ( $₫)$

Department of Dermatology, Saarland University

Medical Center, Homburg, Sarr, Germany

e-mail: cornelia.mueller@uks.eu

S. Smola

Institute of Virology, Saarland University Medical

Center, Homburg, Saar, Germany

\section{INTRODUCTION}

The human papillomavirus (HPV), of which more than 200 different types have so far been identified, is an infectious disease impacting skin and mucous membranes. It is classified into five genera: $\alpha, \beta, \gamma, \mu, v[2,3]$, the alpha genus being the most important for medical practice. These are also known as genital or mucosal types which are divided into high-risk and low-risk types. Persistent infections with mucosal high-risk, and therefore oncogenic, HPV types (such as HPV 16 and 18) are associated with ano-genital and head-neck (mainly HPV 16) neoplasia. Low-risk genital types are, for instance, responsible for condylomata acuminata (HPV 6 and 11) $[5,6]$. The beta genus includes cutaneous types of HPV. Those of the species $\beta 1$ have recently been associated with the pathogenesis of non-melonama skin cancer. $\beta$-HPV types, such as the rare $\beta 1$-HPV-type 47 identified in our patient, were primarily isolated from lesions of patients diagnosed with epidermodysplasia verruciformis (EV), an extremely rare autosomal disorder [3-12]. The $\beta 1-\mathrm{HPV}$ type 47 is among others responsible for pityriasis-like plaques in the case of $\mathrm{EV}$; however, it has also been detected in squamous cell carcinomas of EV patients [9]. In our case, the clinical presentation showed itself analogous to hypopigmented lesions of a pityriasis versicolor 


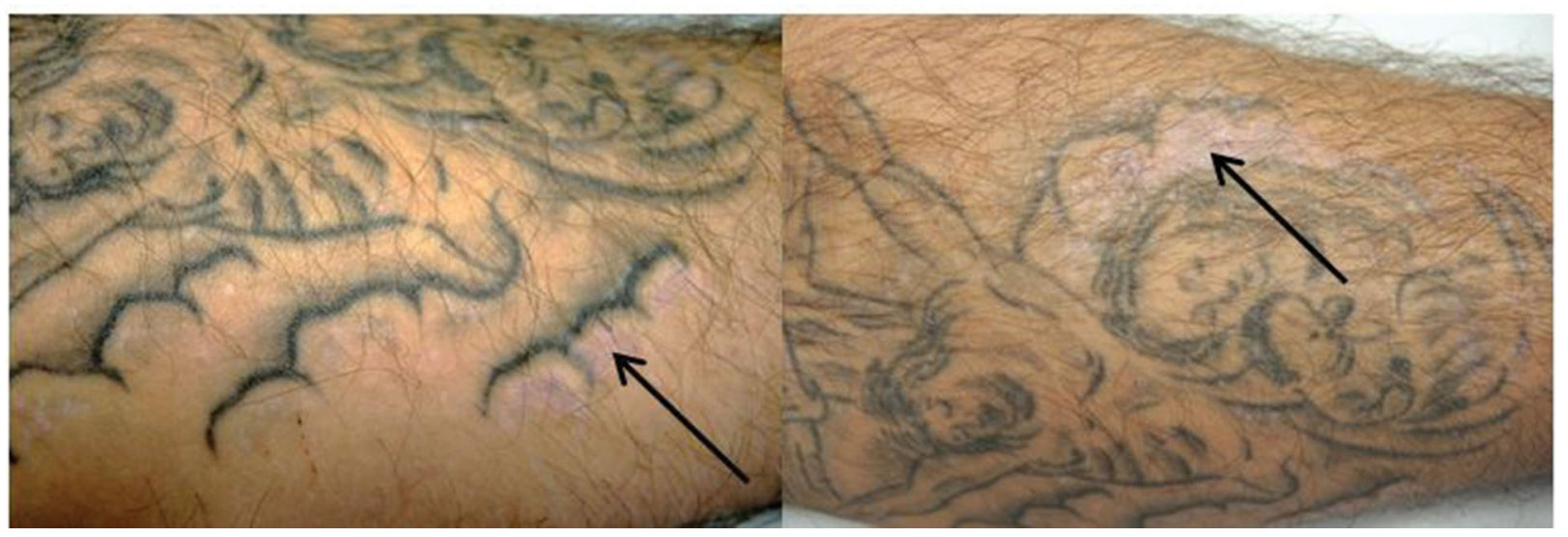

Fig. 1 Hypopigmented, shiny maculae within a tattoo on the left upper forearm

(Fig. 1). The role of $\beta$-HPV types in terms of skin carcinogenesis in the normal population is as yet unknown [5, 7-10, 13].

\section{CASE PRESENTATION}

We present the case of a 48-year-old male patient with the diagnosis of plane verrucae vulgares with intralesional proof of $\beta 1-H P V$ type 47 on the edge areas of his tattoos on both forearms (Fig. 1). The tattooing took place 20 years ago, whereas the first cutaneous lesions had been noticed by the patient only 8 years ago. Histologically, a granular hyperparakeratosis and hypergranulosis were observed in addition to multiple clusters of keratinocytes with vacuolar cytoplasm (Fig. 2a, b). Altogether, it appeared as a viral lesion even though there was no akanthopapillomatosis. An immunohistochemical analysis in order to detect HPV by use of the monoclonal murin anti-HPV antibody (Clone K1H8) was initiated (M3528, dilution of 1:50; Agilent Technologies/Dako). This $\alpha H P V$-antibody is specifically immunoreactive on formalin-fixed paraffin-embedded HPV-infected tissue when HPV subtypes 1, 6, $11,16,18,31,33,42,51,52,56$ and 58 are present [1]. This stain distinguished nearly all of the corneocytes in the stratum corneum in a nuclear pattern, while a few nuclei showed reactivity in the stratum granulosum (Fig. 3). In

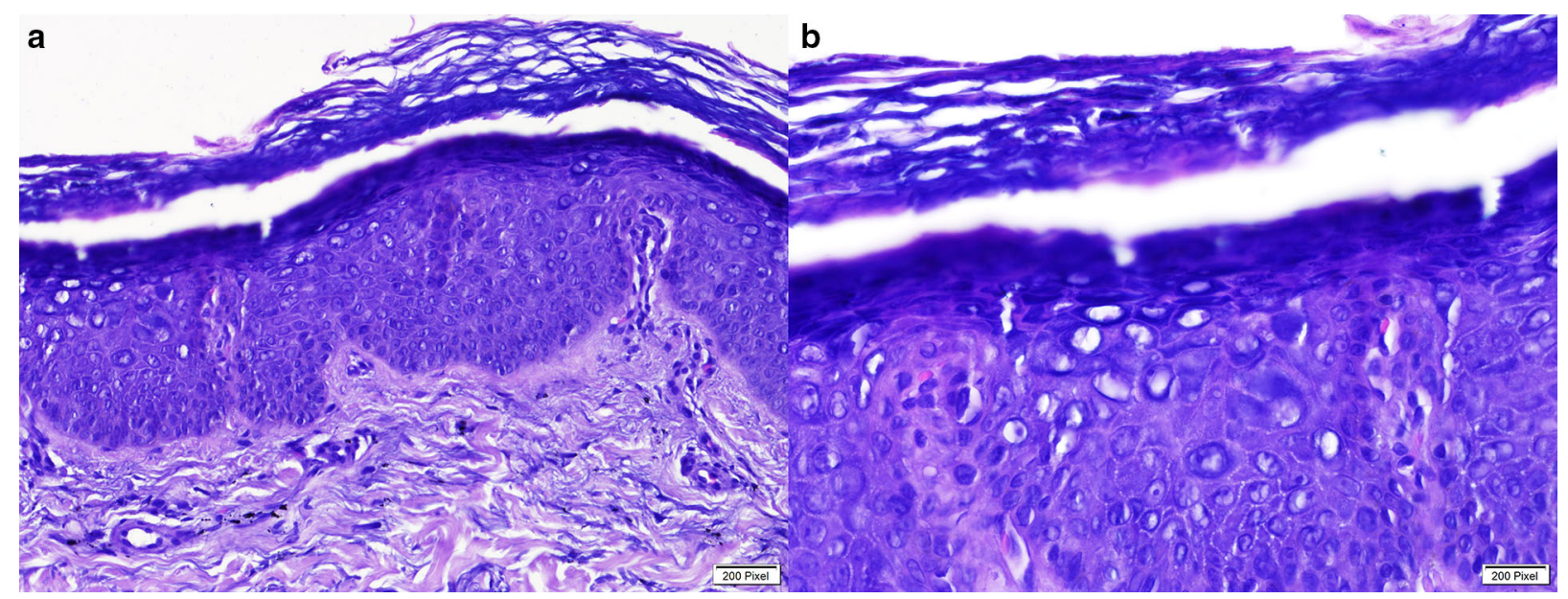

Fig. 2 HE stain of lesional skin. a Original magnification $\times 200$. Granular hyperkeratosis and hyperparakeratosis with cluster of keratinocytes with vacuolar cytoplasm, $\mathbf{b}$ original magnification $\times 400$ 


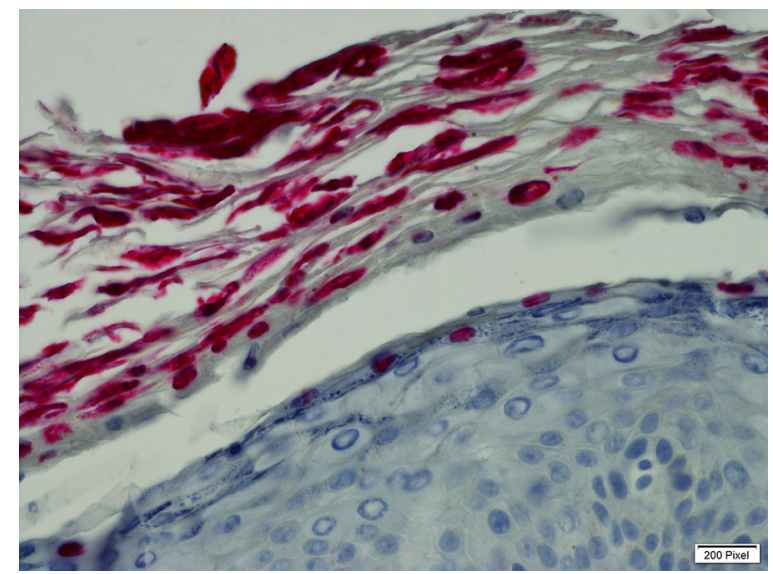

Fig. 3 Anti-HPV stain (Clone K1H8; M3528, dilution $1: 50$, original magnification $\times 400)$. Corneocytes of stratum corneum display positive nuclear stain for human papilloma virus

the subsequently realised virus PCR and consecutive DNA sequencing, we could prove the presence of cutaneous $\beta 1-\mathrm{HPV}$ type 47 DNA. This led to the diagnosis of tattoo-associated verrucae planae, beta1-HPV type 47-induced.

Informed consent was obtained from the patient for being included in this publication.

\section{DISCUSSION}

Currently, an estimated $10 \%$ of the general population and approximately $25 \%$ of the young adult population in Germany is tattooed [14]. However, with tattoos increasing in popularity, a number of mostly cutaneous side effects have also been reported, such as infections, allergic reactions, or even the rise of malignant tumours within the tattoo. While research reports bacterial (e.g., mycobacteriosis), viral (e.g., HPV-induced) and mycotic (e.g., dermatophytosis) infections [6, 15-19], an increasing number of cases with tattoo-associated HPV-induced verrucae can be found in the literature [20-30]. Lately, HPV 27 was identified on warts on tattoos [31].

It is worth considering a possible causality between the proximity of the tattoo and the lesions. While it is possible that the infection was already present before the patient decided to get a tattoo. it might also have been caused by the tattooing. Contamination during tattooing could occur via the instruments or the colors used, even the tattooist's saliva could be in fault [20]. An interesting theory stipulates that virus replication may be activated by mechanical impairment of the skin barrier. Indeed, there are clues that cutaneous HPV are excessively activated in people suffering from psoriasis, or in the case of patients in which reparation processes of the skin take place [32-34]. The hair follicle is regarded as the natural reservoir for the beta HPVs. It may also be possible that the virus was released from the hair follicle caused by the act of tattooing [35-37].

There seems to be a latency period between the act of tattooing and the onset of verrucae, which ranges from 2 months to more than 10 years in our case [20-31]. This delayed replication of the virus could be directly related to sun exposure, as it has been shown that UV exposure can induce a direct activation of closely related $\beta 1-\mathrm{HPV}[38,39]$, and is believed to modulate specific and unspecific responses of the immunological system. This mechanism is thus believed to impair the resistance towards infections, including those that are HPV induced [3, 13, 40-43].

As the $\beta 1-\mathrm{HPV}$ type 47 has, among others, been isolated from cutaneous lesions in patients with $\mathrm{EV}$, the question as to whether $\mathrm{EV}$ can be excluded in our patient has to be addressed. Clinically, the patient had no other lesions than those mentioned earlier. Nor was there palmar or plantar involvement, and neither were there any lesions seen on the patient's face. As we would have expecte an earlier onset of the condition and development of carcinomas considering the patient's age, the diagnosis of EV seems unlikely in our case [4, 7].

Different treatment options (e.g., cryotherapy, curettage, podophyllotoxin or topical imiquimod) of viral warts on tattoos have been reported with mixed results [20-31]. In our case, we started a local off-label use therapy with Veregen ${ }^{\circledR} 10 \%$ ointment (green tea leaf extract), having had good results in using it for treatment of genital warts. The mode of action of this therapy remains unclear, however. It is believed that it originates from the 
anti-oxidative effect of the sinecatechines present in the leaves of green tea, while antiproliferative and antiviral actions should also be considered $[43,44]$.

\section{CONCLUSIONS}

To our knowledge, this is the first documented case of a $\beta 1$-HPV-type infection in cutaneous lesions in terms of verrucae vulgares near a tattoo in an immunocompetent adult without pre-existing conditions. HPV47 belongs to the $\beta$-HPV types which are associated with a higher risk of malignancy in EV patients. The histological image of plane verrucae can be inconclusive in punch biopsies as this rather simple histology may be a challenge, even for a trained dermatopathologist, without clinical observations or photo-documentation of the clinical finding. In this context, the immunohistochemical analysis may prove helpful, although not all types of viruses are caught by the earlier mentioned antibody. According to the data sheet of this antibody, HPV type 47 is not listed as reactive [1]; however, in our case, the anti-HPV-antibody was strongly positive. We were therefore able to demonstrate that the monoclonal murine anti-HPV (Clone K1H8) shows immunoreactivity not only in the presence of the above-named subtypes but also in the case of an infection by $\beta 1$-HPV type 47 . In this case, we recommended that the patient undergoes regular follow-ups. Without the knowledge of the histology, this would surely not have been a standard proposal in the event of an unspecific finding in a tattoo.

\section{ACKNOWLEDGEMENTS}

No funding or sponsorship was received for publication of this article. The article processing charges were funded by the authors. All named authors meet the International Committee of Medical Journal Editors (ICMJE) criteria for authorship for this manuscript, take responsibility for the integrity of the work as a whole, and have given final approval for the version to be published.
Disclosures. Nathalie Krecké, Sigrun Smola, Thomas Vogt and Cornelia Sigrid Lissi Müller have nothing to disclose.

Compliance with Ethics Guidelines. Informed consent was obtained from the patient for being included in this publication.

Open Access. This article is distributed under the terms of the Creative Commons Attribution-NonCommercial 4.0 International License (http://creativecommons.org/licenses/ by-nc/4.0/), which permits any noncommercial use, distribution, and reproduction in any medium, provided you give appropriate credit to the original author(s) and the source, provide a link to the Creative Commons license, and indicate if changes were made.

\section{REFERENCES}

1. Iwasaki T, Sata T, Sugase M, Sato Y, Kurata T, Suzuki $\mathrm{K}$, et al. Detection of capsid antigen of human papillomavirus (HPV) in benign lesions of female genital tract using anti-HPV monoclonal antibody. J Pathol. 1992;168(3):293-300.

2. Bernard HU, Burk RD, Chen Z, van Doorslaer K, zur Hausen $\mathrm{H}$, de Villiers EM. Classification of papillomaviruses (PVs) based on 189 PV types and proposal of taxonomic amendments. Virology. 2010;401(1):70-9.

3. Bolatti EM, Chouhy D, Hosnjak L, Casal PE, Kocjan BJ, et al. Natural history of human papillomavirus infection of sun-exposed healthy skin of immunocompetent individuals over three climatic seasons and identification of HPV209, a novel betapapillomavirus. J Gen Virol. 2017;98(6):1334-48.

4. Przybyszewska J, Zlotogorski A, Ramot Y. Re-evaluation of epidermodysplasia verruciformis: reconciling more than 90 years of debate. J Am Acad Dermatol. 2017;76(6):1161-75.

5. Cubie HA. Diseases associated with human papillomavirus infection. Virology. 2013;445(1-2):21-34.

6. Handisurya A, Schellenbacher C, Kirnbauer R. Diseases caused by human papillomaviruses (HPV). J Dtsch Dermatol Ges. 2009;7(5):453-66 (quiz 66, 67).

7. Adachi A, Kiyono T, Hayashi Y, Ohashi M, Ishibashi M. Detection of human papillomavirus (HPV) type 47 DNA in malignant lesions from epidermodysplasia verruciformis by protocols for precise typing 
of related HPV DNAs. J Clin Microbiol. 1996;34(2):369-75.

8. Quint KD, Genders RE, de Koning MN, Borgogna C, Gariglio M, Bouwes Bavinck JN, et al. Human beta-papillomavirus infection and keratinocyte carcinomas. J Pathol. 2015;235(2):342-54.

9. Smola S. Human papillomaviruses and skin cancer. Adv Exp Med Biol. 2014;810:192-207.

10. Wang J, Aldabagh B, Yu J, Arron ST. Role of human papillomavirus in cutaneous squamous cell carcinoma: a meta-analysis. J Am Acad Dermatol. 2014;70(4):621-9.

11. Adachi A, Yasue H, Ohashi M, Ishibashi M. A novel type of human papilloma virus DNA from the lesion of epidermodysplasia verruciformis. Jpn J Cancer Res. 1986;77(10):978-84.

12. Kiyono T, Adachi A, Ishibashi M. Genome organization and taxonomic position of human papillomavirus type 47 inferred from its DNA sequence. Virology. 1990;177(1):401-5.

13. Antonsson A. Review: antibodies to cutaneous human papillomaviruses. J Med Virol. 2012;84(5):814-22.

14. Stirn A, Brahler E, Hinz A. Prevalence, sociodemography, mental health and gender differences of tattooing and body piercing. Psychother Psychosom Med Psychol. 2006;56(11):445-9.

15. Cruz FA, Lage D, Frigerio RM, Zaniboni MC, Arruda LH. Reactions to the different pigments in tattoos: a report of two cases. An Bras Dermatol. 2010;85(5):708-11.

16. Kaur RR, Kirby W, Maibach H. Cutaneous allergic reactions to tattoo ink. J Cosmet Dermatol. 2009;8(4):295-300.

17. Kluger N, Cohen-Valensi R, Nezri M. Black lymph nodes-and a colourful skin. Lancet. 2008;371(9619):1214.

18. Mataix J, Silvestre JF. Cutaneous adverse reactions to tattoos and piercings. Actas Dermosifiliogr. 2009;100(8):643-56.

19. Oanta A, Irimie M. Tinea on a Tattoo. Acta Dermatovenerol Croat. 2016;24(3):223-4.

20. Ramey K, Ibrahim J, Brodell RT. Verruca localization predominately in black tattoo ink: a retrospective case series. J Eur Acad Dermatol Venereol. 2016;30(10):34-6.

21. Kluger N. Viral warts and seborrhoeic keratoses on tattoos: a review of nine cases. J Eur Acad Dermatol Venereol. 2017;31(7):e340-42.
22. Watkins DB. Viral disease in tattoos: verruca vulgaris. Arch Dermatol. 1961;84:306-9.

23. Young DF, Cole GW. The verrucous mermaid. Int J Dermatol. 1979;18:816-7.

24. Baxter SY, Deck DH. Tattoo-acquired verruca plana. Am Fam Physician. 1993;47:732.

25. Miller DM, Brodell RT. Verruca restricted to the areas of black dye within a tattoo. Arch Dermatol. 1994;130:1453-4.

26. Ragland HP, Hubbel C, Stewart KR, et al. Verruca vulgaris inoculated during tattoo placement. Int J Dermatol. 1994;33:796-7.

27. Trefzer U, Schmollack KP, Stockfleth E, et al. Verrucae in multicolored decorative tattoo. J Am Acad Dermatol. 2004;50:478-9.

28. Saez M, Rodriguez-Martin M, Sidro-Sarto M, et al. Multiple verrucae vulgaris in a young woman's tattoo. J Eur Acad Dermatol Venereol. 2006;20:356-7.

29. Jung JY, Shin HS, Won CH, Cho S. Facial verruca plana that developed after semipermanent tattooing. Ann Dermatol. 2009;21:92-4.

30. Brajac I, Loncarek K, Stojnic-Sosa L, Gruber F. Delayed onset of warts over tattoo mark provoked by sunburn. J Eur Acad Dermatol Venereol. 2005;19(2):247-8.

31. Wanat KA, Tyring S, Rady P, Kovarik CL. Human papillomavirus type 27 associated with multiple verruca within a tattoo: report of a case and review of the literature. Int $\mathrm{J}$ Dermatol. 2014;53(7):882-4.

32. Favre M, Majewski S, Noszczyk B, Maienfisch F, Pura A, Orth G, et al. Antibodies to human papillomavirus type 5 are generated in epidermal repair processes. J Invest Dermatol. 2000;114(3):403-7.

33. Favre M, Orth G, Majewski S, Baloul S, Pura A, Jablonska S. Psoriasis: a possible reservoir for human papillomavirus type 5 , the virus associated with skin carcinomas of epidermodysplasia verruciformis. J Invest Dermatol. 1998;110(4):311-7.

34. Majewski S, Jablonska S. Do epidermodysplasia verruciformis human papillomaviruses contribute to malignant and benign epidermal proliferations? Arch Dermatol. 2002;138(5):649-54.

35. Köhler A, Forschner $\mathrm{T}$, Meyer $\mathrm{T}$, Ulrich $\mathrm{C}$, Gottschling M, Stockfleth E, et al. Multifocal distribution of cutaneous human papillomavirus types in hairs from different skin areas. Br J Dermatol. 2007;156:1078-80. 
36. Plasmeijer EI, Neale RE, Buettner PG, de Koning $\mathrm{MN}$, Ter Schegget J, Quint WG, et al. Betapapillomavirus infection profiles in tissue sets from cutaneous squamous cell-carcinoma patients. Int $\mathrm{J}$ Cancer. 2010;126:2614-21.

37. Neale RE, Weissenborn S, Abeni D, Bavinck JN, Euvrard $S$, et al. Human papillomavirus load in eyebrow hair follicles and risk of cutaneous squamous cell carcinoma. Cancer Epidemiol Biomarkers Prev. 2013;22(4):719-27.

38. Akgul B, Lemme W, Garcia-Escudero R, Storey A, Pfister HJ. UV-B irradiation stimulates the promoter activity of the high-risk, cutaneous human papillomavirus 5 and 8 in primary keratinocytes. Arch Virol. 2005;150(1):145-51.

39. de Villiers EM, Ruhland A, Sekaric P. Human papillomaviruses in non-melanoma skin cancer. Semin Cancer Biol. 1999;9(6):413-22.

40. Ekstrom J, Muhr LS, Bzhalava D, Soderlund-Strand A, Hultin E, Nordin P, et al. Diversity of human papillomaviruses in skin lesions. Virology. 2013;447(1-2):300-11.

41. Korner R, Pfohler C, Vogt T, Muller CS. Histopathology of body art revisited-analysis and discussion of 19 cases. J Dtsch Dermatol Ges. 2013;11(11):1073-80.

42. Shinohara MM, Nguyen J, Gardner J, Rosenbach M, Elenitsas R. The histopathologic spectrum of decorative tattoo complications. J Cutan Pathol. 2012;39(12):1110-8.

43. Nguyen HP, Doan HQ, Brunell DJ, Rady P, Tyring SK. Apoptotic gene expression in sinecatechins-treated external genital and perianal warts. Viral Immunol. 2014;27(10):556-8.

44. Scheinfeld N. Update on the treatment of genital warts. Dermatol Online J. 2013;19(6):18559. 